\title{
What Does A Culture of Corporate Social Responsibility "Look" Like? A Glimpse into a Brazilian Mining Company
}

\author{
Fernanda Duarte \\ University of Western Sydney
}

\begin{abstract}
Based on an exploratory study carried out in 2008 on a Brazilian mining corporation, this paper contributes to the field of business anthropology by applying the notion of organizational culture within the specific context of Corporate Social Responsibility (CSR). It is based on the assumption that organizations that consciously embrace values such as social justice and environmental sustainability develop rich "CSR cultures" over time with specific structures, practices and symbolic manifestations. This type of organizational culture shapes the company's identity, purpose, and outlook, generating unique histories and meanings. The first part of the paper defines the notion of CSR culture and describes the conceptual framework used in the study; the second discusses the qualitative methodology used to gather and interpret the data, and the third maps the key features of the CSR culture in a Brazilian mining company, according to the proposed framework.
\end{abstract}

\section{INTRODUCTION}

The notion of organizational culture emerged in the 1980s and has since generated a robust body of work with numerous definitions and heated debates on what constitutes an "organizational culture" (see for example Deal and Kennedy 1982; Hamada, 1999; Hamada and Sibley, 1994; Kreps, 1981; Louis, 1980; Martin, 2002; Pfeffer, 1981; Schein, 2004; Siehl and Martin, 1981; Smircich, 1983). More than two decades later, this concept remains compellingly relevant to make sense of phenomena that unfold in business organizations. Organizational culture, notes business anthropologist Ann Jordan (2009, p.22), is "part of the fabric of an organization and continues to be studied in both management and anthropology because it describes something intangible about organizations."

This paper contributes to the still evolving literature on organizational culture by applying this notion within the specific context of Corporate Social Responsibility (CSR) - defined here as management based on responses to "issues beyond the narrow economic, technical, and legal requirements of the firm" (Davis, 1973, p. 312), in line with wider social and environmental values. While a number of articles have been written over the past few years on CSR within the context of company-community relations (see for example Kapelus, 2002; Rajak, 2008; Raman, 2007; Sharp, 2006; Smith and Helfgott, 2010; Welker, 2009), there seems to be a gap in business 
anthropological research focusing specifically on organizational cultures generated by CSR values, structures, and practices.

This gap is addressed here through the use of a conceptual framework inspired by Smircich (1983) to map out the defining features of the CSR culture of Brazilian mining company. The data emerged from a qualitative research carried out in Brazil in 2008 for the purpose of understanding the complexities of CSR in large corporations in the extractivist sector. The particular company examined in this paper was selected for the study because it was promoted in Brazil as exemplary in terms of CSR policies and programs. The specific focus of the current analysis on a mining company is due to the critical relevance of CSR management in the mining sector in view of its persistent image problems. As commented by Jenkins and Yakovleva (2006, p. 272), "the discovery, extraction and processing of mineral resources is...regarded as one of the most environmentally and socially disruptive activities undertaken by business." They further point out that many of the environmental disasters or human rights infringements that have raised public concern about CSR over the past three decades have occurred in the mining or petroleum industries. As a result, the mining sector tends to have a negative image and reputation associated with "real or perceived poor environmental and social performance" (Walker and Howard 2002, p 9-10).

The first part of the paper defines the notion of CSR culture and describes the conceptual framework used in the study, the second discusses the qualitative methodology used to gather and interpret the data, and the third maps the key features of the CSR culture in a Brazilian mining company, according to the proposed framework.

\section{GRASPING THE “CSR CULTURE" CONCEPT}

As already pointed out, a voluminous academic literature has emerged over the past three decades on the topic of organizational culture (see for example Deal and Kennedy 1982; Hamada, 1999; Hamada and Sibley, 1994; Kreps, 1981; Louis, 1980; Martin, 2002; Pfeffer, 1981; Schein, 2004; Siehl and Martin, 1981; Smircich, 1983). However, not much has been specifically written on the notion of CSR culture. In the literature review, only one short electronic article on this concept, written by Hancock (2005), was identified. In this particular work, the writer examines the characteristics of what she terms an "integrated CSR culture," explaining that "a CSR culture is fundamentally values-driven as opposed to being purely financially-driven, and invariably involves widespread and systemic change in the way that companies do business."

Building on Hancock's definition, CSR culture is conceptualized here as a set of more or less shared meanings underpinned by the notion of sustainability, which give an organization its distinctive character of being ethical, equitable and transparent in relation to people and the environment (based on Smircich, 1983). Thus, a CSR culture enables organizational members to create and sustain a more or less shared view of the world based on commitment to social and environmental values.

In order to understand the unique organizational history and identity generated by a CSR culture, a framework is proposed by this author based on the assumption that shared meanings are enacted within the organization through three dimensions: (i) values and beliefs, (ii) structures and practices, and (iii) symbolic manifestations. The section below explores these three dimensions of a CSR culture which will be applied later to the findings of the study. It must 
be pointed out; nevertheless, that while in real-life these elements are closely intertwined, they will be examined separately for the purpose of this paper.

\section{Values and Beliefs}

Values are ethical ideals that permeate the organizational culture at various levels. They generate a specific type of philosophy which imbues the organization's structures, practices, and discourses (Schein, 2004). Values produce beliefs, or a strong conviction of the "truth" of a certain view of the world more or less shared by organizational members. Values characteristic of the CSR worldview include a sense of fairness and equity, respect for human beings and the environment, and the belief in the importance of ethical behaviour and transparency.

A point often made in the literature is that organizational values are promoted by founders and leaders (see for example Schein, 2004) and are maintained by managers (Desai and Rittenburg, 1997; Drumwright, 1994; Duarte, 2010; Goodpaster and Matthews, 1982; Graafland, Kaptein and Schouten, 2007; Hemingway and Maclagan, 2004; Menon and Menon, 1997; Mosley, Pietri, and Megginson, 1996; Mudrack, 2007; Strautmanis, 2008). As will be discussed later, within the context of the study presented here, this is clearly the case in CSR cultures which emerge because of the leaders' personal belief in and commitment to social justice and ecological sustainability. These values are enacted by managers who are also personally committed to these endeavors.

\section{Structures and Practices}

An organization committed to CSR values develops over time certain structures and positions dedicated specifically to CSR matters (e.g., CSR Divisions or Departments; CSR Managers; Community Relationship Managers and Community Liaison Officers). These structures and positions in turn generate practices that consolidate CSR values. Examples of CSR practices include social or environmental impact assessments, socially based policies such as "work/family balance," environmental protection policies, and community-based initiatives such as health and education programs.

\section{Symbolic Elements}

Symbolic elements are the more abstract components of CSR cultures and include categories such as symbols, language, metaphors, and stories (Driskill and Brenton, 2005). Symbols are artifacts or icons that represent the organization and reaffirm its core values. A company that professes to have a CSR culture enacts its shared meanings through symbolic elements and practices such as a mission statement highlighting CSR values, slogans or logos based on the CSR worldview, websites and reports framed in CSR rhetorical terms, and even architectural and spatial features, as will be seen later.

Language is a core symbolic element of CSR cultures. Indeed, the particular vocabulary used by employees in a given company provides important clues about its organizational culture (Brenton, 1993). In CSR cultures, expressions such as "social investment," "triple bottom line," (1) and "sustainability" are commonly used and are more or less understood by employees.

Metaphor is another component of the symbolic dimension of CSR cultures. It is defined by Lakoff and Johnson (1980, pp. 3-5) as a "device of poetic imagination" that enables us to understand and experience "one kind of thing in terms of another." For example, in companies committed to CSR, managers and employees sometimes use the metaphor of the family to describe their work experience (this theme which will be further explored later). 
Stories are narratives about people and events which organizational members create and tell newcomers or outsiders. These narratives encourage employees to accept the organization's core values or norms (Driskill and Benson, 2005). In companies committed to CSR, staff from CSR divisions or departments often tell stories about significant people and events associated with positive social and/or environmental performance (e.g.: achievements of CSR champions; memorable celebrations involving local communities; successful CSR programs and their benefits to the community).

Having discussed the proposed three-tiered conceptual framework, we now proceed to apply this framework to the findings of a qualitative study which will bring to life the CSR culture of a Brazilian mining corporation. But first it is essential to make a few points about the qualitative methodology used in the study.

\section{CSR CULTURE IN A BRAZILIAN COMPANY: THE STUDY}

Reported in this paper is what Czarniawska (1997, p. 65) would portray as a "window study" - a qualitative research technique in which the researcher opens "an arbitrary time window" to describe all that she can see through it during a pre-established period of time. The window opened by this researcher was a six-week fieldwork carried out between August and September in 2008 in a major Brazilian city. The purpose of this study was to collect data on CSR initiatives in companies involved in extractivist activities. This research project produced five window studies, and this paper discusses the findings of one of them, which focused on the company that appeared the most strongly committed to social and environmental responsibility.

The rationale for the qualitative design is that approaches of this nature enable researchers to explore individual or collective understandings and reconstruction of complex social phenomena. Data gathering techniques such as open-ended, face-to-face interviews encourage the participants to reflect more deeply on their personal experience. The spontaneous responses elicited by qualitative research methods, in turn, enable researchers themselves to engage in more intensive reflective "brainwork," as they "ponder the impressions and deliberate on recollections and records" of their research (Stake, 2005, pp 449-450).

Purposive sampling was used for study, which means that the researcher consciously targeted a certain population (in this case staff in a mining corporation working in the area of CSR) because of its particular relevance to the study and of their potential to help develop explanations for the phenomenon under examination (Mason, 1996). The sample included two CSR managers, two company employees and nine community members; a total of 13 people. The use of such a small sample can be justified on the grounds that the study was not concerned with representativeness and/or generalizability. Rather, the participants were selected because they had varying degrees of knowledge about the CSR culture that endowed their company with its unique history and identity. This enabled them to provide rich descriptions of their experiences with CSR in their job.

The primary data collection technique was face-to-face, open-ended interviews based on a previously prepared interview schedule covering the following points:

1. Historical background of CSR in the company

2. Participant's perceptions in relation to organizational values

3. Overview of existing CSR structures and initiatives

4. Participant's own values 
5. Participant's role in the CSR division of the company

6. Whether they believed there was a "CSR culture" in the company, and how they felt about it

7. Examples of specific practices of their CSR culture

8. Examples of specific rituals carried out to enact CSR values

The interviews were treated as informal conversations, which allowed the participants to be more relaxed and open in their responses. The interviews were recorded with the participants' permission and later transcribed and sent back to them for verification. Following the participants' approval of the transcripts, the relevant sections were selected and translated into English by the researcher who is herself a native Portuguese speaker. To ensure anonymity and confidentiality, the names of the company, geographic locations, and interviewees have been replaced by pseudonyms.

In addition to data obtained in the interviews, this paper uses data from corporate documents such as annual reports, publicity materials, and company website. It also presents materials derived from the author's informal observations and fieldwork notes. This means that what is presented here is to a large extent a reconstruction of the "official" view promoted by the company on its CSR activities.

Presented here is an interpretive study based on the author's own interpretation of the qualitative data gathered during fieldwork. There is thus no pretence of objectivity or impartiality. Qualitative epistemology is based on the assumption that there is no such a thing as value-neutral research; that it is not possible to faithfully "mirror" a social phenomenon without distortion (Martin 2002:173). As pointed out by Denzin and Lincoln (2005, p. 6; 22) research is an "interactive process shaped by [the researcher's] own personal history, biography, gender, social class, race and ethnicity, and by those of the people in the setting." What the researcher constructs, based on the data obtained in the field, reflects their values and interests. This is particularly true in relation to phenomena as complex and multi-layered as CSR culture, which cannot be studied as a "thing" that exists out there, that can be objectively perceived and measured by the researcher who studies it. Moreover, interpretations cannot be consensual because the same phenomenon may have different meanings for different researchers. "What may seem objectively true at one time is subject to revisions, as it changes, and as apparent understanding change" (Martin, 2002, p.35).

\section{The Company}

Fictitiously named "Ferrus" for the purpose of the study, the organization under discussion was a leading mining corporation located in a major Brazilian city, with more than 3,000 employees and a robust financial performance. Notwithstanding the image problems commonly faced by mining companies, Ferrus enjoyed a relatively good reputation - to a considerable extent because of its strong CSR culture which was consciously developed and promoted by its CEOs and strategists. The Company's CSR culture was enacted and sustained by a team of dedicated and loyal managers and employees, with ongoing support of organizational leaders. Drawing on data from the study, the sections below will illustrate the three dimensions of Ferrus' CSR culture, namely, values and beliefs, practices and structures, and symbolic manifestations. 


\section{CSR Values and Beliefs}

As previously pointed out, values and beliefs shape organizational philosophy which in the case of Ferrus was based on CSR concepts such as social justice, respect for human life and the environment, ethical behaviour and transparency. Ferrus' CSR values were highlighted, for example, in the organization's mission statement:

"We endeavour to foster social, economic and environmental development through the responsible use of resources and the forging of lasting relationships with our stakeholders. We are guided by principles such as respect for human beings, justice and collective well-being. We establish transparent and ongoing relationships with our stakeholders, based on ethics and aimed at generating value for all" (Ferrus' Annual Report).

Ferrus' CSR values gave rise to, and were enacted in, certain structures and practices especially created to administer CSR related matters, implement social and environmental policies, and manage special social and environmental programs for communities located in the vicinity of the Company.

The interview with "Carlos," a senior executive of Ferrus' Sustainability Division concurs with Collier and Esteban's (2007) suggestion that the "tone from the top" is important to develop and sustain a CSR based culture. Carlos established a direct link between the social justice values of the company's CEOs and the emergence of commitment to CSR. According to him, the CEOs had always been actively involved in corporate citizenship activities, in particular volunteer work in local communities. He pointed out that the leaders' personal values had been instrumental in the conceptualization of Ferrus' Social Investment Policy which guided the implementation of community projects. In Carlos' own words:

"Yes, I believe [that the personal values of leaders play a role in the decision to introduce CSR], and we see this in our own administration. Our leaders are exemplary; that is, they see our social policies as values of our organization. Ferrus' CEO is the President of [the local Chamber of Commerce]. Our Director of Sustainability Operations is an active participant in our volunteering program. [...] Our leaders were the great initiators of our Social Investment Policy."

Carlos highlighted human respect, in particular, as an organizational value that lay at the core of the CSR programs offered by Ferrus to local communities:

"When you talk about human respect, you're not merely talking about the internal environment of the organization. You're also talking about its external environment. This value guides our actions. That is, I'm part of the community. I participate in this community; therefore I ought to respect these people. [...] Ferrus is widely known in Brazil for its strong engagement in social action. That's what makes us different from other companies."

The material presented above illustrates the critical role played by values such as respect for people and the environment in the creation of CSR cultures. As will be seen below, CSR values generate specific structures, practices and symbolic forms. 


\section{CSR Structures and Practices}

The central CSR structure at Ferrus was the Sustainability Division which reported directly to the CEO, reflecting its high status within the Company. It was pointed out by Carlos that the Sustainability Division had been created by the CEO himself for the specific purpose of conceptualizing, implementing, and monitoring CSR based policies and programs. A core component of this organizational structure was the Community Relationships Unit (CRU) which mediated between the Company and local communities and also delivered special CSR programs and campaigns for employees (e.g., "Stop Smoking Campaign"; "Get Fit Program"; "Eat Well Program"). The CRU was also responsible for the administration of the Centre for Community and Environmental Education, described in Ferrus' publicity documents as "a space for dialogue with local communities" and "a repository of regional socio-environmental information." The Centre was routinely used for special CSR related events (e.g., launch of CSR programs) and for lectures on relevant environmental issues.

The Sustainability Division was directly responsible for the implementation of the Ferrus' environmental management system which included waste management, water resource management, rehabilitation of affected areas, atmospheric emission management, and environmental education. The Division was also responsible for the provision of special training and retraining for employees involved in the delivery of CSR programs and for fostering positive relationships with local communities. These were considered the Company's primary stakeholders, as Ferrus' extractivist activities directly affected the people who lived in the area. (It could be suggested in fact that Ferrus' license to operate was granted in exchange for initiatives that benefited local communities and repaired the environmental damage inflicted by mining operations.)

According to the CSR managers interviewed for the study, the most important achievement of the Sustainability Division over the past few years had been the development and implementation of the Social Investment Policy. Its aim embodied the organization's core CSR value "to contribute towards sustainable, integrated, local development of society, knowing and respecting its potential, values and interests" (Ferrus' publicity brochure). The influence of CSR beliefs and values on the Social Investment Policy is evident in the statement below from one of the Company's annual reports examined for the study:

"The Social Investment policy was created with the objective to improve the quality of life and work conditions of Ferrus' employees. It is also a form of compensate local communities for the disruptions caused by the activities associated with the Company's expansion. The Policy is the result of the responsibility and values that have always guided the Company, generating and encouraging sustainable development."

Another example of CSR-specific practices at Ferrus was the community based programs through which the organization's values were routinely enacted. At the time of this study there were more than 30 community projects in progress, including oral hygiene and health education programs in local primary schools, income generation programs for women, and entertainment for local communities in the form of theatre plays and outdoor cinemas. There were also initiatives designed to have long-term, "transformative goals," as described by Carlos, including courses on environmental education, leadership and management skills, vocational skills, and income generation programs. As commented by Community Relationships Manager "Lucia": 
"Ferrus has been directly responsible for my professional development...and I wouldn't be where I am without the training opportunities it gave me. I feel very privileged to work here."

CSR practices at Ferrus also included "certifications" - that is, written assurance by an independent third party that the Company's products and services conformed to specific requirements. Ferrus had all the major CSR based certifications, including ISO 14000 (environmental management), ISO 9001 (quality control), and OHSAS 18001 (occupational health and safety) (2). As proudly stated in one of the reports consulted for this study, "Ferrus was one of the first mining companies in the world to receive the ISO 14001 certification for all stages of its production process." The Company also complied with the guidelines of the Global Reporting Initiative (GRI) for economic, social, and environmental indicators, and regularly used the Dow Jones Sustainability Indexes to enhance its sustainability performance (3).

\section{CSR Symbolic Manifestations}

No doubt due to the nature of Ferrus' operations, the themes of environmental protection and ecological sustainability loomed large in the symbolic dimension of its organizational culture. For example, the study identified a number of slogans that conveyed environmental protection symbolism. One such slogan was "Moving forward towards sustainability," which at the time of the study appeared in all of its promotional documents and reports. This slogan explicitly constructed sustainability as the core goal of Ferrus. In the same vein, a slogan that appeared on the cover of a past annual report stated: "Sustainability is the fruit of Ferrus' development over the past three decades." Ecological sustainability also informed two statements that flickered alternately on the homepage of the Company's website: "Ferrus: always in harmony with the natural environment and communities," and "The iron Ferrus obtains from nature comes back as environmental protection."

Symbolic manifestations associated with environmental protection were also observed during a visit by the researcher to one of the Company's plant. She was taken by one of the Sustainability Division managers on a tour of the area surrounding the plant complex. This 20acre site was described on a placard as "Ferrus' own Ecological Sanctuary" [Santuário Ecologico] and was rich in environmental sustainability symbolism. For example, along the cement pathway that structured the Passeio Ecológico [Ecological Walk], there were several signs describing the particular types of native plant and animal species which Ferrus contributed to preserve through its on-going environmental management programs. The signs contained colorful illustrations of native birds characteristic of that habitat, including Jacu, Jacupenha, Inhambuaçu and Macuco. The Passeio Ecológico was a powerful symbolic device used to convey to the visitor the message that Ferrus was "a company that cared for the environment."

Symbolic manifestations associated with social responsibility were also observed during the window-study, in both visual and written forms. For example, a recurrent pattern in Ferrus' reports and publicity materials was pictures of smiling employees donning uniforms and safety helmets emblazed with the Company logo. In these pictures, Ferrus' employees were often portrayed side-by-side with equally smiling, healthy looking community members, connoting harmonious relationships between the Company and local communities. Posters with similar social responsibility themes adorned the walls of the boardroom of Ferrus' head office. One of these posters contained the caption: "Ferrus: Ligada a Comunidade" ["Ferrus: Connected with the Community"]. 
CSR symbolism was also reflected in Ferrus' endorsement of aspirational texts such as the United Nations Global Compact and the Millennium Development Goals in its Annual Reports; it was also a member of Transparency International (4). This symbolized the Company's commitment to human rights, environmental protection, and the fight against corruption at a global level, which enhanced the Company's status as a socially and environmentally responsible organization. As affirmed in one of the Annual Reports consulted for this study:

"Ferrus' practices and relationships seek to respect and defend the universal values of human rights, labour standards, environmental protection and the fight against corruption, in compliance with the Global Compact proposed by the United Nations (UN) and endorsed by Ferrus. The Principles of the Compact are reflected in the Company's strategic objectives, in its Code of Conduct (provided to all employees), and its Integrated Management System. The Company also supports the Millennium Goals, translated into programs focused on the Company's internal public, the formation of strategic partnerships and the assurance of sustainability".

With regard to CSR related language, it was evident in the interviews that staff from the Sustainability Division had a shared understanding of a CSR-based vocabulary used to describe processes and events in their daily routines. Expressions such as "sustainability," "environmentally responsible practices," "stakeholders," "triple bottom line," "social investment," "social equity." and "environmental and social performance," figured prominently in the Company's written and spoken discourse. Below is an excerpt from an Annual Report incorporating rhetorical elements characteristic of CSR:

“Ferrus' Integrated Management Policy guides the environmental actions of the Company, focusing on the rational use of natural resources and control of the impacts of its activities, with the ultimate goal of preserving these resources and thus assuring the Company's sustainability. This is based on the management of water resources, reduction of waste generation (as well as its correct disposal), control of atmospheric emissions, rehabilitation of altered areas, preservation of biodiversity and environmental education. The main objective is to promote sustainable development in all areas of influence".

The study also identified the use of metaphor as a symbolic element of Ferrus' CSR culture. As signposted earlier, the "family" metaphor emerged in the comments of the two employees interviewed as a positive descriptor of the Company's working environment. For example, to the question "Do you enjoy working at Ferrus?" Administrative Assistant "Luiz" gave the following answer:

"Yes, I like working at Ferrus because of its atmosfera familiar [family atmosphere]. I think this is very important because you feel free to talk about anything with people. If you have a problem - even a personal problem - you know where to go. If you have a work-related problem, you go to your manager or to the supervisor; or even to your workmates. You can talk about whatever you like. É um clima de irmão mesmo [it's really a brotherly climate]; you're always guided. This makes you feel secure".

Mining operative 'Joaquim' also used a family metaphor in his response to the same question: 
"I'm very proud to have this job. [...] because Ferrus greatly values its employees [...] If something happens here, they're like...family, really. And that's why I say that the Company values $[\ldots]$ all of its employees. So, I have to try to reciprocate by giving the best I can [to the Company]".

As pointed out by Driskill and Brenton (2005, p. 46), the family metaphor is "consistent with the values of caring, nurturing, and permanent commitments." This is perceived by the above employees as integral features of their work experience at Ferrus.

The findings also highlight the role of storytelling as a symbolic element of Ferrus' CSR culture. For example, one of the annual reports examined contained a number of vignettes based on "good news stories" recounted by members of local communities who had benefited from Ferrus' CSR programs. In one such vignette, a woman (who will be referred to as "Tania") told a story that showcased Ferrus' positive social performance. With funding provided through the Company's Social Investment Policy, Tania was able to successfully start her own small business which produced goods made from plastic bottles. In her own words:

"Ferrus' participation in our community is becoming increasingly important to us. We are few, and we do not have many opportunities for employment, but the partnership with the Company has shown us that with simple solutions we can achieve great results. This is the case with the [title omitted to ensure anonymity] Project. In a contest run by Ferrus to raise environmental awareness among the children in our region, our local school won the second prize, and with the prize money the School was able to purchase the machines to recycle plastic bottles which mobilized the women in the community. The project created a new way to generate income for our families. We learned to work together as a team and to think of our future together, as well as to help prevent pollution, since we encourage the collection of plastic bottles to use as raw material for our products".

To the symbolic manifestations identified above, it can be also added organizational rituals as another practice observed during the window-study. For example, it was reported in the interviews that the above mentioned Centre for Community and Environmental Education was regularly used for social gatherings that enabled an interface between Ferrus and its neighbouring communities. These social gatherings can be seen as occasions in which the Company ritually bonded with local communities to celebrate its CSR achievements. "Gloria," a community leader, reported that whenever community groups were successful in their bids for grants for special projects from Ferrus, the Sustainability Division would organize wellpatronized churrascos [barbeque parties] with plenty of cerveja [beer] to celebrate the occasion. In her words, "These events are critically important to create and maintain good relationships with our communities, and they're much appreciated."

Summing up, the data presented in the above sections bring to life the three core dimensions of Ferrus' CSR culture, namely, its values and beliefs, structures and practices, and symbolic manifestations. The findings of this window study have enabled the researcher to map out some key features that can be seen as generic attributes of CSR cultures (see summary in Box 1). It is important to bear in mind, nevertheless, that many of these features overlap with each other (e.g., the Code of Conduct can be seen both as a CSR practice and a symbolic element) and were only listed separately for the sake of simplification. 


\section{BOX 1 \\ DEFINING FEATURES OF FERRUS' CSR CULTURE}

\section{CSR VALUES AND BELIEFS}

1. Leaders and managers claim personal commitment to CSR values such as respect for human life and the environment; transparency; equity; social justice.

2. Social and environmental values are embedded in corporate mission and in the company's business strategy

3. CSR beliefs and values enacted in the company's structures and practices.

\section{CSR STRUCTURES AND PRACTICES}

4. Formalised management framework for CSR, with divisions/departments and positions specifically created to deal with CSR issues (e.g., Sustainability Division; Sustainability Division Director; CSR Managers; Community Liaison Officers)

5. Triple Bottom Line reporting framework.

6. CSR-related International standards certification (e.g., ISO 14,001; OHSAS 18,001)

7. Company reports to global CSR entities such as GRI, Global Compact Account Ability.

8. Social responsibility and environmental indicators (e.g.: Dow Jones)

9. Environmental and human resources management systems

10. A well articulated and apparently effective Social Investment Policy

11. CSR initiatives and programs regularly carried out in line with the Social Investment Policy (e.g., Oral Hygiene in Schools program; leadership development courses)

12. CSR initiatives and programs regularly monitored and evaluated

13. Regular engagement and consultation with local communities as primary stakeholders

14. Dialogue with environmental and social justice NGOs

15. CSR officers regularly trained and re-trained in areas relevant to CSR management

16. A significant amount of space in the Company's Annual Report devoted to CSR issues

\section{CSR SYMBOLIC MANIFESTATIONS}

17. Slogans and logos promoting social and/or environmental values

18. Pervasive use of CSR terminology (e.g., triple bottom line; social investment; sustainability; community consultation, etc)

19. Code of conduct emphasizing social and/or environmental values

20. In publicity materials, company highlights external recognition of its CSR activities (e.g. national and international awards; Dow Jones); links with renowned CSR organizations such as the Ethos Institute of Social Responsibility

21. Company publicizes the fact that it is a signatory of the Global Compact/Millennium Goals/ Transparency International.

22. Employees (including those outside CSR structures) demonstrate awareness of CSR initiatives in the Company

23. Symbolic utilization of space to promote environmental responsibility: Santuario Ecologico [Ecological Sanctuary]; Passeio Ecologico [Ecological Walk)

24. Regular celebration of CSR achievements through events with the community (e.g.: celebration of successful community grants)

25. Use of "family" metaphor (by employees and managers) as a descriptor of the company's work environment.

26. Stories highlighting success with CSR initiatives

27. Promotional materials such as brochures and posters highlight CSR as a core practice of the company (e.g., posters showing smiling employees and community members). 


\section{SUMMARY AND CONCLUSIONS}

Based on a window-study of a Brazilian mining corporation, the author has provided an interpretive account of how this company represented its CSR culture to the outside world. Data from corporate documents, semi-structured interviews with managers and employees, and observation enabled the researcher to categorize the features of Ferrus' CSR culture into three interrelated dimensions: values, organizational structures and practices, and symbolic manifestations. It was contended that Ferrus' CSR values generated specific structures and positions (e.g., Sustainability Division; Community Relationships Manager) dedicated to the elaboration, implementation and monitoring of CSR based practices (e.g., health and education programs for local communities). CSR values were also found to generate specific symbolic practices such as specialized language, evocative metaphors, stories and celebratory rituals. Borrowing from Schein $(2004$, p. 8; 15), it can be said that the shared meanings that underpinned Ferrus' CSR culture generated a 'patterning' which integrated various organizational elements into a larger paradigm or gestalt (that is, a functional unit whose properties are more than the summation of its parts). This perceived stability created an illusion that the company was, in its totality, equitable, environmentally aware, ethical, and transparent.

The contribution of this paper to the field of business anthropology is threefold: first and foremost, it has demonstrated that the notion of organizational culture is still useful to understand organizational phenomena such as CSR, as it acknowledges its complex and multi-layered nature; second, the study has enabled a better understanding of what CSR cultures "look like" and how they are enacted and sustained over time by organizational members; third, the paper offered a three-dimensional framework, based on existing studies of organizational cultures, to map out the defining features of a CSR culture in mining corporations. This framework may be useful to understand the phenomenon in other types of companies in the extractivist sector.

However, it is also important to recognize that the study on which the paper is based has some limitations. First, as a "window-study" it only has limited explanatory power, as it addresses the theme of CSR culture over a restricted timeframe. As already pointed out, what is presented here was largely based on the "official view" of CSR promoted by the organization to external publics. Future ethnographic studies of CSR cultures should be carried out over longer periods for a more comprehensive, in-depth analysis of the phenomenon. Future research should explore in greater depth, for example, the specific role of the personal values of managers in sustaining a CSR culture. It would also be appropriate to gather data outside the company's CSR structures, in order to investigate whether employees from other areas of the organization have the same enthusiasm and commitment in relation to CSR as staff working directly with it. This would enable a more thorough analysis of what has been described here as a "CSR culture," in order to find out the extent to which it permeates the organization as a whole. It would also be interesting to investigate whether CSR cultures necessarily lead to an "ethical climate" (Cullen, Parboteeah and Victor, 2003; Victor and Cullen, 1988) or a shared perception of how to engage in ethical conduct within the organization. Studies of this type would be most beneficial to companies committed to CSR as they would provide data which could help CSR managers to more consciously monitor performance in the three dimensions examined in the study.

Finally, and most importantly, it must also be emphasized that the CSR culture conceptual framework proposed by the author is only a heuristic device for business scholars and practitioners to "think with." As admonished by Jordan (2009, p. 22), cultures "never existed as 
closed systems." In a rapidly changing and complex world, conceptions of neatly bounded, static organizational cultures are largely implausible.

\section{ENDNOTES}

1 - The term "triple bottom line" was coined by John Elkington in his influential book Cannibals with Forks: the Triple Bottom Line of 21 st Century Business (1997). It refers to an accounting system that goes beyond the traditional financially-based reporting framework to take into account ecological and social performance.

2 - ISO (International Organization for Standardization) is a non-government network of the national standards institutes of 163 countries with a Central Secretariat in Geneva, Switzerland. Its purpose is to develop and publish International Standards achieved through consensus agreements between national delegations representing the economic stakeholders concerned suppliers, users and, often, governments. The stakeholders agree on specifications and criteria to be applied consistently in the classification of materials, the manufacture of products and the provision of services (Source: ISO website). OHSAS 18000 is an international occupational health and safety management system specification (Source: OHSAS 18000 website).

3 - The Global Reporting Initiative is a global multi-stakeholder network of experts from dozens of countries worldwide, who have developed a sustainability reporting framework setting out principles and indicators that can be used to measure and report their economic, environmental, and social performance (Source: GRI website). The Dow Jones Sustainability Indexes are a subset of the Dow Jones Indexes which track the financial performance of the leading companies worldwide, providing asset managers with benchmarks to manage sustainability portfolios. Based on research by Sustainable Asset Management (SAM) - an asset management company headquartered in Zurich - the Dow Jones Sustainability Indexes rank companies within their industry group and select the leading companies in terms of sustainability for the Dow Jones Sustainability Indexes. (Source: Dow Jones Sustainability Indexes website).

4 - The United Nations Global Compact is "a strategic policy initiative for businesses that are committed to aligning their operations and strategies with ten universally accepted principles in the areas of human rights, labour, environment and anti-corruption" (Source: UN Global Compact website). The Millennium Development Goals are a set of goals outlined in the United Nations Millennium Declaration (adopted in 2000) which commit the signatories to a new global partnership to address problems such as extreme poverty, the spread of HIV/AIDS, corruption and lack of educational opportunities in developing countries by the target date of 2015 (Source: Millennium Development website). Transparency International (TI) is a politically non-partisan worldwide coalition of more than 90 national chapters formed in 1993 to address the problem of corruption. TI's mission is "to create change towards a world free of corruption" by bringing together relevant players from government, civil society, business and the media to promote transparency in elections, in public administration, in procurement and in business. (Source: TI website) 


\section{REFERENCES}

Brenton, A. L. (1993). Demistifying the Magic of Language: Critical Linguistic Case Analysis of Legitimation of Authority. Journal of Applied Communication Research, 21(3), 227-244.

Collier, J., and Esteban, R. (2007). Corporate Social Responsibility and Employee Commitment. Business Ethics, 16(1), 19-33.

Cullen, J. B., Parboteeah, P., and Victor, B. (2003). The Effects of Ethical Climate on

Organizational Commitment: A two-study analysis. Journal of Business Ethics, 46(2): 127-141.

Czarniawska, B. (1997). Narrating the Organization: Dramas of Institutional Identity. Chicago: The University of Chicago Press.

Davis, K. (1973). The Case For and Against Business Assumption of Social Responsibilities. Academy of Management Journal, 16(2): 312-322.

Deal, T. E., and Kennedy, A. A. (1982). Corporate Cultures: The Rites and Rituals of Corporate Life. Reading, MA: Addison-Wesley.

Denzin, N. K., and Lincoln, Y. S. (Eds.). (2005). The Sage Handbook of Qualitative Research (Third ed.). London: Sage.

Desai, A., and Rittenburg, T. (1997). Global Ethics: An Integrative Framework for MNEs. Journal of Business Ethics, 16(8): 791-800.

Dow Jones Sustainability Indexes http://www.sustainability-index.com/, accessed on 29.11.2010.

Driskill, G. W., and Brenton, A. L. (2005). Organizational Culture in Action: A Cultural Analysis Workbook. Thousand Oaks: Sage Publications.

Drumwright, M. (1994). Socially Responsible Organisational Buying: Environmental Concern as a Noneconomic Buying Criterion. Journal of Marketing, 58 (Jul), 1-19.

Duarte, F. (2010). Working with Corporate Social Responsibility in Brazilian Companies: The Role of Managers' Values in the Maintenance of CSR Cultures. Journal of Business Ethics, 96(3): 355-368.

Elkington, J. (1997). Cannibals with Forks: the Triple Bottom Line of 21st Century Business, Oxford: Capstone.

Ethos Institute for Business and Social Responsibility, http://www.csr360gpn.org/partners/profile/ethos-institute-of-business-and-social-responsibility/ accessed on 29.11.2010.

Global Reporting Initiative (GRI) http://www.globalreporting.org/Home accessed on 29.11.2010. 
Goodpaster, K. E., and Matthews, J. B. (1982). Can a Corporation Have a Conscience? Harvard Business Review, 60(1): 132-141.

Graafland, J., Kaptein, M., and Mazereeuw - van der Duijn Schouten, (2007). Conceptions of God, Normative Convictions, and Socially Responsible Business Conduct: An Explorative Study Among Executives. Business and Society, 46(3): 331-378.

Hamada, T. (1999). Practicing Anthropology in Business Organizations. Practicing Anthropology 21(4): 2-4.

Hamada, T., and Sibley, W. E. (Eds.). (1994). Anthropological Perspectives on Orrganizational Culture. Lanham, MD: University Press of America.

Hancock, K. (2005). Employee Engagement Partnerships: Can they Contribute to the Development of an Integrated CSR culture? Partnership Matters: Current Issues in Cross-Sector Collaboration, Retrieved from http://www.cpi.cam.ac.uk/pdf/partnershipmatters3.pdf on $13 / 01 / 2009$

Hemingway, C., and Maclagan, P. (2004). Managers' Personal Values as Drivers of Corporate Social Responsibility. Journal of Business Ethics, 50(1): 33-41.

Jenkins, H., and Yakovleva, N. (2006). Corporate Social Responsibility in the Mining Sector: Exploring Trends in Social and Environmental Disclosure. Journal of Cleaner Production, 14(34): 271-284.

Jordan, A. T. (2009). The Importance of Business Anthropology: Its Unique Contributions. International Journal of Business Anthropology, 1(1): 15-25.

International Standards Organization, http://www.iso.org/iso/home.htm, accessed on 29.11.2010.

Kapelus, P. (2002). Mining, Corporate Social Responsibility and the "Community": The Case of Rio Tinto, Richards Bay Minerals and the Mbonambi. Journal of Business Ethics, 39(3): 275296.

Kreps, G. (1981, July). Organizational Folklore: The Packaging of Company History at RCA. Paper presented at the ICA/SCA Conference on Interpretive Approaches to Organizational Communication, Alta.

Lakoff, G., and Johnson, M. (1980). Metaphors we Live By. Chicago: the University of Chicago Press.

Louis, M. (1980). A Cultural Perspective in Organizations: The Need for and Consequences of Viewing Organizations as Culture-Bearing Milieux. Paper presented at the National Academy of Management Meeting, August Detroit. 
Martin, J. (2002). Organizational Culture: Mapping the Terrain. London: Sage Publications.

Menon, A., and Menon, A. (1997). Enviropreneurial Marketing Strategy: The Emergence of Corporate Environmentalism as Market Strategy. Journal of Marketing, 61(Jan): 51-67.

Millennium Development Goals http://www.un.org/millenniumgoals/ accessed on 29.11.2010.

Mosley, D., Pietri, P. H., and Megginson, L. C. (1996). Management: Leadership in Action. New York: Harper Collins.

Mudrack, P. (2007). Individual Personality Factors that Affect Normative Beliefs About The Rightness of Corporate Social Responsibility. Business and Society, 46(1): 33-62.

Occupational Health and Safety Standards 18000, http://www.ohsas-18001-occupational-healthand-safety.com/, accessed on 29.11.2010.

Pfeffer, J. (1981). Management as Symbolic Action: The Creation and Maintenance Of Organizational Paradigms. In L. Cummings and B. Staw (Eds.), Research in Organizational Behavior. Greenwood, CT: JAI Press: 1-52.

Rajak, D. (2008). 'Uplift and Empower': The Market, Morality and Corporate Responsibility on South Africa's Platinum Belt. In D. Wood (Ed.), Hidden Hands in the Market: Ethnographies of Fair Trade, Ethical Consumption, and Corporate Social Responsibility - Research in Economic Anthropology. 28: 297-324.

Raman, K. R. (2007). Community-Coca-Cola Interface: Political-Anthropological Concerns on Corporate Social Responsibility. Social Analysis, 51(3): 103-120.

Schein, E. (2004). Organizational Culture and Leadership. San Francisco, CA: Jossey-Bass.

Sharp, J. (2006). Corporate Social Responsibility and Development: An Anthropological Perspective. Development Southern Africa, 23(2): 213-222.

Siehl, C., \& Martin, J. (1981). Learning Organizational Culture, Working Paper, Graduate School of Business. Stanford University.

Smircich, L. (1983). Concepts of Culture and Organizational Analysis. Administrative Science Quarterly, 28(Sep), 339-358.

Smith, J., and Helfgott, F. (2010). Flexibility or Exploitation? Corporate Social Responsibility and the Perils of Universalization Anthropology Today, 26(6): 20-23.

Stake, R. E. (2005). Qualitative Case Studies. In N. Denzin, K and Y. S. Lincoln (Eds.), The Sage Handbook of Qualitative Research. Thousand Oaks, London, New Delhi: Sage. 
Strautmanis, J. (2008). Employees' Value Orientation in the Context of Corporate Social Responsibility. Baltic Journal of Management, 3(3): 346-356.

Transparency International (TI) http://www.transparency.org/, accessed on 29.11.2010.

United Nations Global Compact, http://www.unglobalcompact.org/, accessed on 29.11.2010.

Victor, B., and Cullen, J. (1988). The Organizatinoal Basis of Ethical Work Climates.

Administrative Science Quarterly. 33(1): 101-125.

Welker, M. A. (2009). Corporate Security Begins in the Community: Mining, the Corporate Social Responsibility Industry, and Environmental Advocacy in Indonesia. Cultural Anthropology, 24(1): 142-179. 